\title{
Stroke and the Orthopaedic Surgeon
}

\author{
BANSKOTA AK
}

B and B Hospital, Kathmandu University Teaching Hospital, Gwarko, Lalitpur, Nepal

\begin{abstract}
The role that can be effectively played by the orthopaedic surgeon in the long-term management of the stroke victim is often overlooked. Post-stroke patients rely heavily on the orthopaedist, amongst other members of the multidisciplinary team, to regain the maximum possible functional status following the stroke event. A great need to understand and implement the principles of post-stroke orthopaedic treatment and rehabilitation exists in our own community and practice.
\end{abstract}

\section{INTRODUCTION:}

Most patients who survive a stroke in our country have little or no knowledge about the available options for orthopaedic/rehabilitation care. As the average age of our population increases, the number of stroke survivals is also likely to increase. It is estimated that $60 \%$ of the survivors are able to achieve some degree of rehabilitation. ${ }^{1-5} \mathrm{~A}$ basic review of the pathophysiology, critical evaluation tools and challenges to orthopaedic management is presented in an effort to highlight and increase the awareness of treatment options amongst our medical community when evaluating a stroke victim for prognostication and potential functional gains.

\section{STATISTICS:}

Although there are no available statistics for Nepal, it is becoming increasingly apparent that medical conditions predisposing to stroke (hypertension, diabetes, hyperlipediaemias etc.) are showing increasing trends in our own population. It is estimated that there are 500,000 to 700,000 new cases of stroke in the USA annually., It is reported by some that about $80-90 \%$ of patients survive their stroke, often with significant sequel while others claim that almost $50 \%$ of stroke patients succumb within 3 weeks of the event. Anywhere between 50-60\% of those who survive the initial vascular insults survive an additional 5 years; $20 \%$ of survivors are known to require custodial care..$^{1,7,9,14,15}$ How this category of stroke victims are managing in our communities is a matter of speculation!

\section{TYPES OF CVA AND SURVIVAL:}

Cerebral thromboemboli account for nearly $69 \%$ of strokes followed by intracerebral hemorrhage (12\%), subarachnoid hemorrhage (11\%) and ill-defined lesions $(11 \%) .{ }^{1,7,8,9}$ In the USA, there is an incidence of one stroke victim every 45 seconds. ${ }^{8,9}$

\section{ANATOMY:}

The internal carotid artery system supplies blood to the anterior brain through the anterior and middle cerebral arteries. Involvement of the middle cerebral artery results in contralateral hemiplegia, hemianesthesia, homonymous hemianopia and aphasia (for the dominant hemisphere).

The anterior cerebral artery affliction results in paralyzing the opposite foot or leg with lesser degree of arm involvement, mental impairment and frontal release signs.

\section{RISK FACTORS:}

Hypertension is a strong identified risk factor. Diabetes mellitus, obesity, contraceptive use, cigarette smoking and coronary heart disease have been implicated but no conclusive evidence yet exist to show that these factors increase the risk of stroke.

Restoration of function following stroke: ${ }^{1,15,16,17}$

Stroke patients have approximately six months following their onset during which they make spontaneous neurologic recovery. Important determinants in the recovery process include the size of the lesion and the amount of collateral circulation in the region.

Motor recovery pattern: There is a definitive motor restoration sequence in stroke. The initial phase of flaccid paralysis is followed by a phase of mass flexor synergism (proximal to distal joints) characterized by hyperactive 
tendon reflexes. Mass extensor synergism then follows from proximal to distal joints. Selective flexion of individual joints is followed by a concurrent decrease in the flexor tone. Persistent flaccidity beyond four weeks for lower extremity and beyond six weeks for upper extremities spells a poor prognosis, with these patients often requiring wheelchairs and institutionalization.

Sensory recovery: It is well known that a limb that lacks sensation lacks function. Touch and pain sensations return in the majority and some claim that they are never lost. A well-documented progression of sensory recovery is lacking as in the motor system.

\section{There are a few situations where a worse prognosis is} likely:

1. Lesions in the parietal lobe in the dominant hemisphere leads to loss of body balance

2. Communication loss (aphasia, dysarthria)

3. Impairment of mentation

4. Hemianopsia/ hemianesthesia

Other factors that result in adverse outcome include:

1. Lack of family support

2. Persistent bowel/bladder incontinence. These functions usually recover within a day or two in most hemiplegics.

3. Prior CVA, bilateral involvement, suggestive of severe arteriosclerosis.

4. Pseudobulbar palsy: (Emotional incontinence, bilateral disease, dysarthria, dysphagia)

5. Pathological reflexes ( glabellar, snout)

Physiotherapy is initiated once the patient is medically stable. As already mentioned, most spontaneous recovery occurs during the first six months. The patient must be able to balance on the uninvolved side before gait training can begin. There are only limited benefits of initiating physiotherapy a year after the stroke event.

Non - Operative Treatment Principles: $:^{1,2,4,6,13}$
Upper extremity: Train in all activities of daily living as one extremity individual. If there is neurological recovery in the affected extremity, it can be used for assistive functions.

Early contracture prevention is achieved by positioning, range of motion exercises and splinting. Initially help may be required and later the patient learns to perform independently. Later, strengthening program is implemented for muscles of the normal limb as well as for the muscle groups antagonistic to the spastic ones.

The shoulder has a tendency to contract in adduction and internal rotation and the elbow is in excessive flexion from hyperkinesia and later contracture. Painful contractures of the hand are best prevented by early splinting in functional position and initiation of ADL's. Injection of tender points and peripheral nerves (sensocaine, phenol etc.), use of icepacks, TENS and splinting measures all form a part of the general modalities for management.

Summary of surgical procedures commonly undertaken for the upper and lower extremities ${ }^{10}$

The hemiplegic lower limb presents problems at the ankle, knee and hip. Range of motion several times daily in addition to appropriate splinting is generally adequate to prevent contractures in the ankle and knee. Flexion and adduction deformity in the hip can be prevented by prone positioning several times daily and with the use of abduction pillows. In the initial phases, prevention of knee and ankle contractures by positioning and splinting is crucial. Orthoses play an important role but they need to be of light material and user friendly in terms of donning on and removal. Some patients will require wheelchairs.

The indications for operative treatment in the stroke patient include hygiene, facilitating nursing care, pain relief and improvement in function. The goals can be achieved to varying degrees by procedures designed to eliminate or prevent the effects of spasticity and by tendon lengthening or tendon transfers.

A summary of surgical procedures commonly undertaken for the upper and lower extremities is given in Tables 1 and 2 respectively: ${ }^{10}$ 
Table 1

\begin{tabular}{ll}
\hline Thumb in palm deformity & $\begin{array}{l}\text { Flexor pollicis lengthening } \\
\text { or thenar muscle transfer } \\
\text { Finger flexion deformity }\end{array}$ \\
& $\begin{array}{l}\text { Sublimis to profundus } \\
\text { transfer in non-functional } \\
\text { hands; muscle tendon } \\
\text { lengthening in functional } \\
\text { hands }\end{array}$ \\
Wrist flexion deformity & $\begin{array}{l}\text { Wrist flexor release } \\
\text { Musculocutaneous } \\
\text { Elbow flexion deformity }\end{array}$ \\
& neurectomy
\end{tabular}

Table 2

\begin{tabular}{|c|c|}
\hline Equinus & Achilles tendon lengthening \\
\hline Varus & $\begin{array}{l}\text { Split anterior tibial tendon } \\
\text { transfer }\end{array}$ \\
\hline Claw toe & Toe flexor release \\
\hline Inadequate knee flexion & $\begin{array}{l}\text { Rectus femoris and vastus } \\
\text { intermedius release }\end{array}$ \\
\hline $\begin{array}{l}\text { Hip and knee flexion } \\
\text { contractures }\end{array}$ & $\begin{array}{l}\text { Hamstring and hip flexor } \\
\text { release }\end{array}$ \\
\hline $\begin{array}{l}\text { Adduction, internal } \\
\text { rotation contractures of } \\
\text { the shoulders }\end{array}$ & $\begin{array}{l}\text { Adductors, internal rotators } \\
\text { release }\end{array}$ \\
\hline
\end{tabular}

\section{DISCUSSION:}

The orthopaedic specialist in Nepal seldom encounters a stroke patient at an appropriate time frame when interventions might be of benefit. Stroke patients have approximately six months following the event during which they make spontaneous neurologic recovery. No definitive tendon surgery should be done during this period. ${ }^{1,13,15,16,17}$ Preventive/ non-operative methods must be implemented with full force, taking the family into confidence and maximally utilizing all the physiotherapy and occupational therapy resources available.

It is essential to understand the indications as well as the limitations of surgery in the stroke victim. Surgical procedures will improve function only in those cases where the major factor interfering with function is spasticity. If the problem is abnormal sensation, perceptual problems, cognitive function or co-ordination abnormalities, surgery is unlikely to improve the patient's functional requirements. ${ }^{10}$

The highly sophisticated and complex nature of the normally functioning upper extremity is impossible to restore following a stroke, regardless of etiology., ${ }^{2,413}$ One third of the patients recover sufficiently to the extent to utilize an involved upper limb as an assistive device. When the normal function of the brain is disrupted by brain pathology (as in stroke), the integration of a large number of afferent impulses is affected leading to the loss in the ability to perform fine, well co-ordinated motor activities. $^{1,5}$

Prehension, manipulation and the ability to transfer objects is severely impaired. Motor recovery alone is inadequate for upper extremity utility following stroke and in such an extremity, the useful function would be limited to use as an assistive limb only. ${ }^{5,6,16}$

Nearly half to three fourths of patients with stroke recover sufficiently to ambulate. When available, gait analysis is of immense help in planning surgery. The firing sequence of muscles during activity change following a stroke or head injury and the altered patters are inconsistent from one patient to another. Electromyography, gait analysis assist in preventing unnecessary lengthening or releases of phasic and appropriate muscles which can lead to opposite deformity. Generally, flexor synergy is useful in swing phase and extensor synergy in the stance phase of gait. $6,12,17,18$

Orthotic rehabilitation plays a very important role in the management of the residua of stroke., ${ }^{1,2,3,10,11,13,18}$ Inadequate hip and knee flexion results in inability to initiate swing and foot drag. An elastic strap may be used as an assistive hip flexor device till muscle tone improves. Otherwise such a patient will need to use a wheelchair. Extensor insufficiency at the knee can be managed with a stabilizing knee orthosis. There is no effective knee surgery to restore knee extension. In the absence of useful recovery, the patient will again be relegated to wheelchair ambulation.

There is no effective orthotic device to treat inadequate hip extension. Hip-Knee-Ankle-Foot-Orthosis (HKAFO) is generally a cumbersome appliance with limited benefit. If extensor tone develops, ambulation may be possible and if this does not occur, wheelchair is the answer.

For knee recurvatum, a floor reaction principle ankle foot orthosis may work. Judicious heel cord lengthening may be the answer for equinus deformity at the ankle. 


\section{CONCLUSION:}

We need to look at our stroke patients more critically to see how complications can be prevented and functional improvements rendered. Accurate prediction of function in a stroke patient is difficult and there exists a great variability in the extent of involvement and sequel..$^{1,9,14,15,16,17}$ Surgery needs to be undertaken very judiciously, only after careful and thorough evaluation.

\section{REFERENCES:}

1. Post stroke rehabilitation: Assessment, referral and patient management. US department of health and human services public health service agency for health care policy and research. Clin Pract Guide/ Quick Ref Guide Clin 1995; 16: $1-32$

2. Botte MJ, Waters RL, Keenan MA, Jordon C, Garland DE: Approaches to senior care \#3: Orthopaedic management of the stroke patient 2: Treating deformities of the upper and lower extremity. Orthop Rev 1988; 17: 891 - 910

3. McCollough NC 3: Orthotic management in adult hemiplegia. Clin Orthop Relat Res. 1978; 131: 38 - 46

4. McCollough NC 3: The role of orthopaedic surgeon in the treatment of stroke. Orthop Clin North Am. 1978; 9: 305 324

5. Botte MJ, Waters RL, Keenan MA, Jordon C, Garland DE: Approaches to senior care \# 2: Orthopaedic management of the stroke patient 1: Pathophisiology, limb deformity and patient evaluation. Orthop Rev. 1988; 17: 637 - 647

6. Garland DE, Waters RL: Orthopaedic evaluation in hemiplegic stroke. Orthop Clin North Am. 1978; 9: 291 304

7. Broderick, J. P.; Phillips, S. J.; Whisnant, J.P.; O’Fallon, W. M.; and Bergstralh, E. J.: Incidence rates of stroke in the eighties: the end of the decline in stroke? Stroke 1989; 20:577-582.

8. Broderik J, Brott T, Kothari R et al. The Greater Cincinnati/ Northern Kentucky Stroke Study: Preliminary first-ever and total incidence rates of stroke among blacks. Stroke. 1998; 29: $415-421$
9. Rathore SS, Hinn AR, Cooper LS, Tyroler HA, Rosamond WD: Characterization of incident stroke signs and symptoms: Findings from the artherosclerosis risk in communities study. Stroke. 2002; 33: $2718-2721$

10. Ranchos Amigos Rehab Center Bulletin. Downey, California

11. Mooney V, Perry J, Nickel VL. Surgical and non-surgical orthopaedic care of stroke. J of Bone and Joint Surg AM. 1967; 49: $989-1000$

12. Kramers De Qurvain, Ines A, Simon SR, Leurgans S, Pease WS., Mcallister D. Gait Pattern in the Early Recovery Period after Stroke. J Bone Joint Surg [Am] 1996; 78-A; 1506-14

13. Cladwell CD, Wilson DJ, Braun RM. Evaluation and treatment of the upper extremity in the hemiplegic stroke patient. Clin Ortho Relat Res. 1969; 63: 69-93

14. Skilbeck, C. E.; Wade, D. T.; Hewer, R. L.; and Wood, V. A.: Recovery after stroke. J. Neurol., Neurosurg., and Psychiat. $1983 ; 46: 5-8$

15. Bach-y-Rita, P., and Balliet, R.: Recovery from stroke. In Stroke Rehabilitation: the Recovery of Motor Control, pp. 79-108. Edited by P. W. Duncan and M. B. Badke. Chicago, Year Book Medical, 1987

16. Wade, D. T.; and Hewer, R. L.: Functional abilities after stroke: measurement, natural history and prognosis. J. Neurol., Neurosurg., and Psychiat. 1987; 50:177-182.

17. Wade, D. T.; Wood, V. A.; Heller, A.; Maggs, J.; and Langton Hewer, R.: Walking after stroke. Measurement and recovery over the first 3 months. Scandinavian J. Rehab. Med. 1987; 19:25-30.

18. Perry, J., and Montgomery, J.: Gait of the stroke patient and orthotic implications. In Stroke Rehabilitation, pp. 246-282. Edited by M. E. Brandstater and J. V. Basmajian. Baltimore, Williams and Wilkins, 1987.

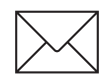

\section{CORRESPONDENCE:}

Dr. Ashok Kumar Banskota

Department of Orthopaedic Surgey

B\&B Hospital

E-mail: bbhospital@wlink.com.np 